\title{
How far away from using Aspirin to Treat Colon Cancer?
}

\author{
Guangyu Wang ${ }^{1}$, Tianzhen Wang ${ }^{2}$, Yunwei Wei ${ }^{3, *}$, Xiaobo $\mathrm{Li}^{2, *}$ \\ ${ }^{1}$ Department of Gastrointestinal Medical Oncology, the Affiliated Tumor Hospital of Harbin \\ Medical University, Harbin, China \\ ${ }^{2}$ Department of Pathology, Harbin Medical University, Harbin, China \\ ${ }^{3}$ Department of General Surgery, the First Affiliated Hospital of Harbin Medical University, \\ Harbin, China \\ 2,"lixiaobo@ems.hrbmu.edu.cn, ${ }^{3 *}$ hydwyw11@hotmail.com
}

\begin{abstract}
The chemoprevention effect of Aspirin has been well recognized until now. Recently, two researches published in Cell (2015; 162: 1257-1270) and Journal of National Cancer Institute (2015; 107(1):345)even suggested the helpful effect of aspirin in the treatment of colon cancer. We summarized the key points of both studies here and initiated a topic: How far away from using aspirin to treat colon cancer?
\end{abstract}

Keywords: Colon Cancer; Aspirin; Immunotherapy; Chemotherapy; cyclooxygenase.

It has been recognized that aspirin is a promising agent for cancer chemoprevention by various epidemiological studies since 1988[1]. Especially, daily aspirin use has been believed to significantly decrease the rate of morbidity and mortality of colon cancer[2, 3]. Recently, two researches even suggested the helpful effect of aspirin in the treatment of colon cancer.

In one research publishedin Cell (2015;162: 1257-1270), Santiago and colleagues showed that aspirin use maybe useful for immune-based therapies in cancer patients also. They firstly found that prostaglandin $\mathrm{E} 2\left(\mathrm{PGE}_{2}\right)$ produced by cancer cells contributed to cancer cells evading anti-tumor immunity through shifting the inflammatory profile in various cancer models. $\mathrm{PGE}_{2}$, produced by cyclooxygenase $(\mathrm{COX})$ in cancer cells, strongly inhibited the production of mediators with cancerinhibitory effects, such as TNF and IL-12, while induced the production of mediators promoting cancer cell growth, such as IL-6 and CXCL1, by bone marrow derived mononuclear cells (BMMCs)[4]. Further they showed that COX inhibition by using aspirin synergized with anti-PD-1 monoclonal antibody based immune checkpoint blockade therapy, a great promising immune therapy aimed at unleashing the anti-cancer potential of tumor-specific $\mathrm{T}$ cells [5, 6], in various cancer models including colon cancer[4].

In another research published in Journal of National Cancer Institute (2015;107(1):345), Kimmie Ng and colleagues reported that aspirin may be effective in the adjuvant therapy of colon cancer. They performed a prospective analysis of aspirin use in stage $\amalg$ colon cancer patients enrolled in a clinic trail, which was originally designed to compare fluorouracil (FU) and leucovorin (LV) with FU, LV plus irinotecan for adjuvant treatment of stage Ш colon cancer (GALGB 89803)[7], they observed that consistent aspirin use during chemotherapy was associated with improved recurrence-free survival (83.1\% vs $74.9 \%$ at five years), disease-free survival $(78.4 \%$ vs $71.1 \%$ at five years), and overall survival (87.6\% vs $80.9 \%$ at five years)[8]. Even this study was based on a self-administered questionnaireanalysis, it provided another emerging evidence that colon cancer patients underwent chemotherapy would be benefit from aspirin use.

Taken together, aspirin may be helpful to treat colon cancer, thus we believe that it is time to test this hypothesis with randomized, multicenter and controlled clinic trail. 


\section{REFERENCES}

[1] Kune GA, Kune S, Watson LF: Colorectal cancer risk, chronic illnesses, operations, and medications: Case control results from the melbourne colorectal cancer study. Cancer research 1988;48:4399-4404.

[2] Rothwell PM, Fowkes FG, Belch JF, Ogawa H, Warlow CP, Meade TW: Effect of daily aspirin on long-term risk of death due to cancer: Analysis of individual patient data from randomised trials. Lancet (London, England) 2011;377:31-41.

[3] Rothwell PM, Price JF, Fowkes FG, Zanchetti A, Roncaglioni MC, Tognoni G, Lee R, Belch JF, Wilson M, Mehta Z, Meade TW: Short-term effects of daily aspirin on cancer incidence, mortality, and non-vascular death: Analysis of the time course of risks and benefits in 51 randomised controlled trials. Lancet (London, England) 2012;379:1602-1612.

[4] Zelenay S, van der Veen AG, Bottcher JP, Snelgrove KJ, Rogers N, Acton SE, Chakravarty P, Girotti MR, Marais R, Quezada SA, Sahai E, Reis ESC: Cyclooxygenase-dependent tumor growth through evasion of immunity. Cell 2015;162:1257-1270.

[5] Page DB, Postow MA, Callahan MK, Allison JP, Wolchok JD: Immune modulation in cancer with antibodies. Annual review of medicine 2014;65:185-202.

[6] Sharma P, Allison JP: The future of immune checkpoint therapy. Science (New York, NY) 2015;348:56-61.

[7] Saltz LB, Niedzwiecki D, Hollis D, Goldberg RM, Hantel A, Thomas JP, Fields AL, Mayer RJ: Irinotecan fluorouracil plus leucovorin is not superior to fluorouracil plus leucovorin alone as adjuvant treatment for stage iii colon cancer: Results of calgb 89803. Journal of clinical oncology : official journal of the American Society of Clinical Oncology 2007;25:3456-3461.

[8] Ng K, Meyerhardt JA, Chan AT, Sato K, Chan JA, Niedzwiecki D, Saltz LB, Mayer RJ, Benson AB, 3rd, Schaefer PL, Whittom R, Hantel A, Goldberg RM, Venook AP, Ogino S, Giovannucci EL, Fuchs CS: Aspirin and cox-2 inhibitor use in patients with stage iii colon cancer. Journal of the National Cancer Institute 2015;107:345. 